\title{
Study on the Practical Use of Urea to Reduce Drying Shrinkage of Concrete by Spraying Urea Solution under Cold Environment
}

\author{
Takumi Sato, Hiromi Fujiwara, Masanori Maruoka and Liu Lingling \\ Graduate School of Regional Development and Creativity, Utsunomiya University, \\ 7-1-2 Yoto, Utsunomiya City, Tochigi Prefecture, Japan, mc196256@cc.utsunomiya-u.ac.jp
}

\begin{abstract}
Concrete cracking caused by drying shrinkage adversely affects the durability of a structure. The results of past research has shown that drying shrinkage can be reduced by adding urea as an admixture to the concrete. However, mixing various admixtures at the factory increases the costs for equipment and labor. To reduce drying shrinkage more easily and inexpensively, the urea solution can be applied to the concrete surface by soaking or brushing. However, urea solutions are not suitable for use in cold weather because urea in solution crystallizes at low temperatures. This study attempted to solve this problem by mixing antifreeze, which resists freezing, with a urea solution. It was found that the crystallization temperature of urea can be lowered by mixing the urea solution the antifreeze. Furthermore, it was confirmed that the antifreeze/urea solution reduced drying shrinkage for both mortar and concrete.
\end{abstract}

Keywords: Urea Solution, Drying Shrinkage, Soaking, Antifreeze, Cold Weather.

\section{Introduction}

Concrete cracking caused by drying shrinkage adversely affects the durability of a structure. Adding urea to concrete is an effective method for reducing drying shrinkage ${ }^{1)}$. However, in ready-mixed concrete factories in Japan, adding various admixture materials to concrete will increase equipment and labor costs. Moreover, drying shrinkage occurs mainly on the surface of concrete, so applying an agent to the surface is more efficient and economical. This paper describes a method of applying urea solution to the surface of concrete after demolding that efficiently and economically reduces drying shrinkage.

\section{Past Achievements}

In previous studies, specimens soaked in a urea solution had less drying shrinkage than untreated specimens (Figure 1). Moreover, the amount of drying shrinkage continue to fall as the soaking time increased ${ }^{2}$. However, soaking concrete in a urea solution of site is not practical, so an experiment was conducted in which urea solution was brushed onto the surface of the concrete. It was found that the brushing method provide an equal or greater effect on drying shrinkage as soaking ${ }^{3)}$.

On the other hand, the specimens had higher compressive strength after soaking in a urea solution, as shown in Figure 2. Moreover, the strength increased as the soaking time increased. These results were likely due to the urea solution entering the concrete and the urea recrystallizing in the voids. The expansion pressure from the urea crystals helped to reduce the drying shrinkage and increase the compressive strength. The water retention effect of the urea crystals may also prevent the dissipation of moisture inside the concrete, which also helped to suppressing drying. 


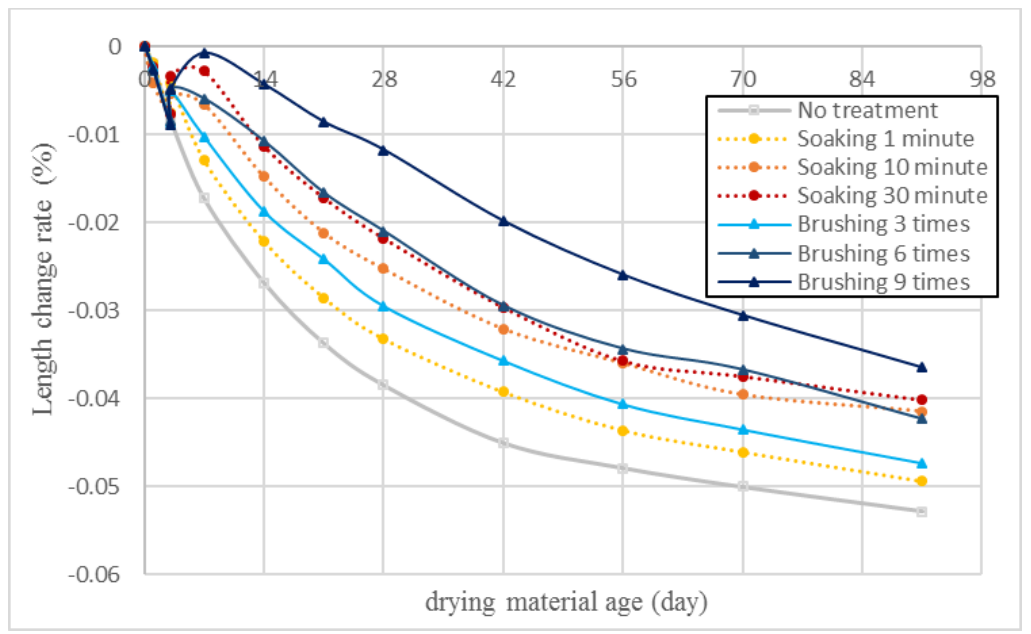

Figure 1. Drying shrinkage reduction.
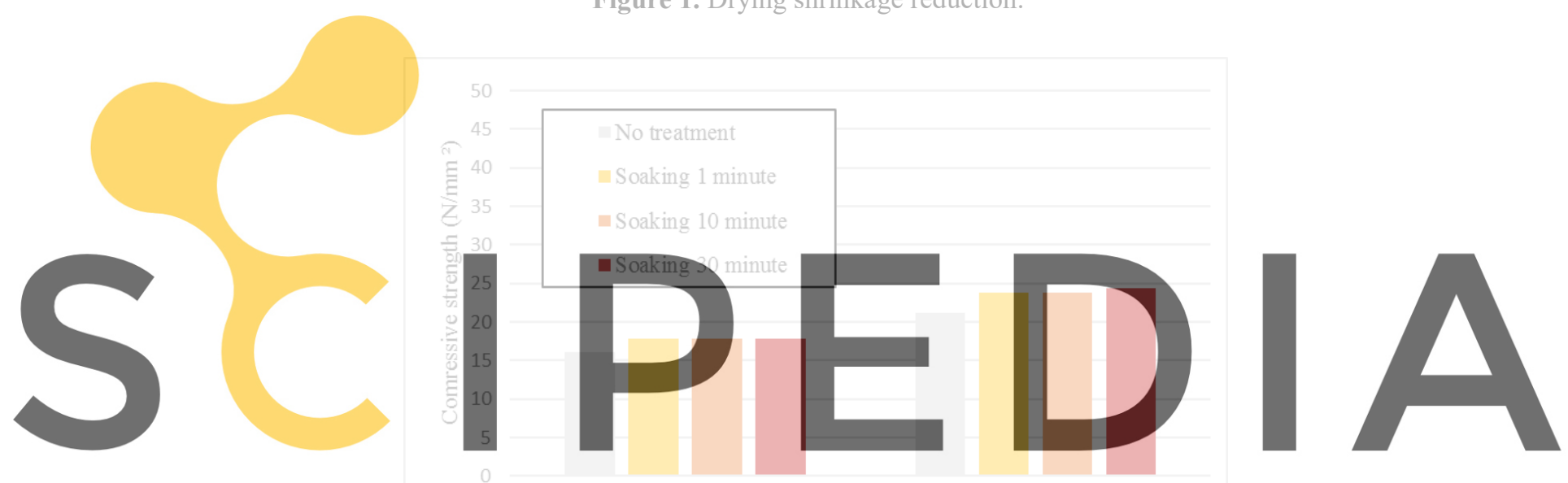

Register for free at https//www.scipedia.com to download the version without the watermark

Figure 2. Result of compressive strength test.

\section{Applying Antifreeze in Cold Weather}

\subsection{Outline}

Previous studies have shown that applying a urea solution to concrete helps to reduce drying shrinkage. However, the solubility of urea decreases at lower temperatures, causing the urea in the water to crystallize and separate out. In cold weather, the urea crystallizes before the solution can be applied to the concrete, thereby reducing the solution's effect on drying shrinkage. To prevent the crystallization of the urea in the solution at low temperatures, antifreeze with freezing resistance was added to the solution. This lowered the crystallization temperature, allowing the urea solution to be used in cold weather.

\subsection{Crystallization Temperature of Urea When Antifreeze is Mixed at Different Rates}

The freezing resistance property of the antifreeze can be varied by adjusting its concentration 
in the urea solution. Therefore, this study investigated the effect of different concentrations of antifreeze on the crystallization temperature of urea in a solution.

\subsubsection{Antifreeze mix solution}

In this test, a commercially available antifreeze used for air conditioner or refrigeration facility was used. The main component of this antifreeze is ethylene glycol. In order to produce different freezing temperatures, the ratio of antifreeze to water were set to $3: 7,4: 6$ and 5:5 (Figure 3). Moreover, in order to make comparisons with a urea solution containing the maximum amount of urea that can dissolve in water at $20\left({ }^{\circ} \mathrm{C}\right)$, the maximum amount of urea that can dissolve at $20\left({ }^{\circ} \mathrm{C}\right)$ was added to the antifreeze solution.
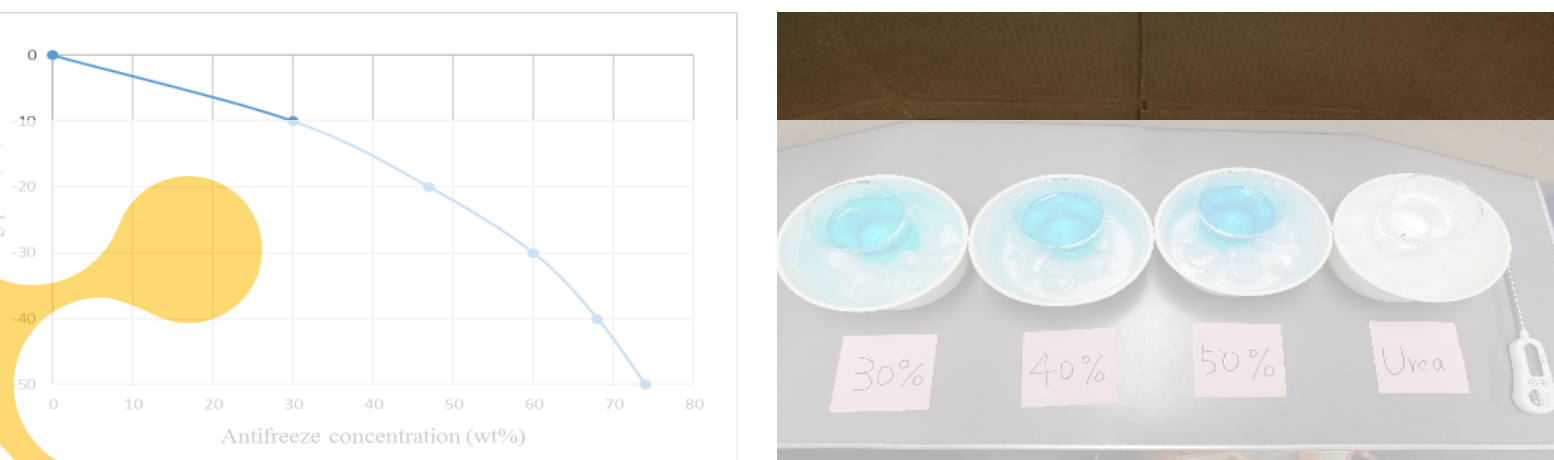

Figure 3. Freezing por

3.2.2 Test method

Photograph 1 shows the different antifreeze con

with different antifreeze concentrations wer

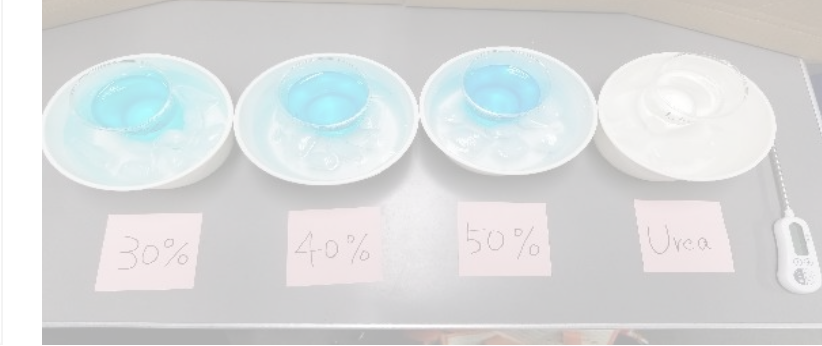

temperature of the solutions was lowered by immersing the containers in ice water. Using a

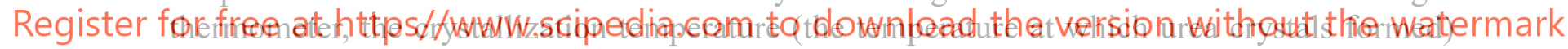

was measured.

\subsubsection{Test result}

As shown in Table 1, the crystallization temperature decreased as the concentration of antifreeze increased. Therefore, it was considered that antifreeze solutions can be applied to concrete in cold weather to reduce drying shrinkage.

Table 1. Crystallization temperature of urea.

\begin{tabular}{|c|c|c|}
\hline \multirow{2}{*}{ Name } & Component (mass ratio) & \multirow{2}{*}{$\begin{array}{c}\text { Crystallization } \\
\text { temperature }\left({ }^{\circ} \mathrm{C}\right)\end{array}$} \\
\cline { 2 - 3 } & Antifreeze $:$ Water : Urea & 5 \\
\hline Antifreeze $30 \%$ & $3: 7: 8$ & 4 \\
\hline Antifreeze $40 \%$ & $4: 6: 7$ & 1 \\
\hline Antifreeze $50 \%$ & $5: 5: 6.5$ & 8 \\
\hline Urea solution & $0: 1: 1$ & \\
\hline
\end{tabular}

\subsection{Effect of a $30 \%$ Antifreeze Solution on Shrinkage Reduction in Mortar}

\subsubsection{Materials}


Table 2 shows the materials used in this test.

\subsubsection{Mix condition}

Table 3 shows the mixing conditions and the properties of the fresh mortar. The target values were $200 \pm 20 \mathrm{~mm}$ for 15 strokes flow, $2.0 \pm 1.5 \%$ for the air volume.

\subsubsection{Mixing method}

For mixing, an omni type mixer with a nominal capacity of 10 liters was used. First, cement and sand were mixed for 15 seconds. Next, water was added and mixed for 60 seconds. Finally, the mortar was discharged.

Table 2. Materials.

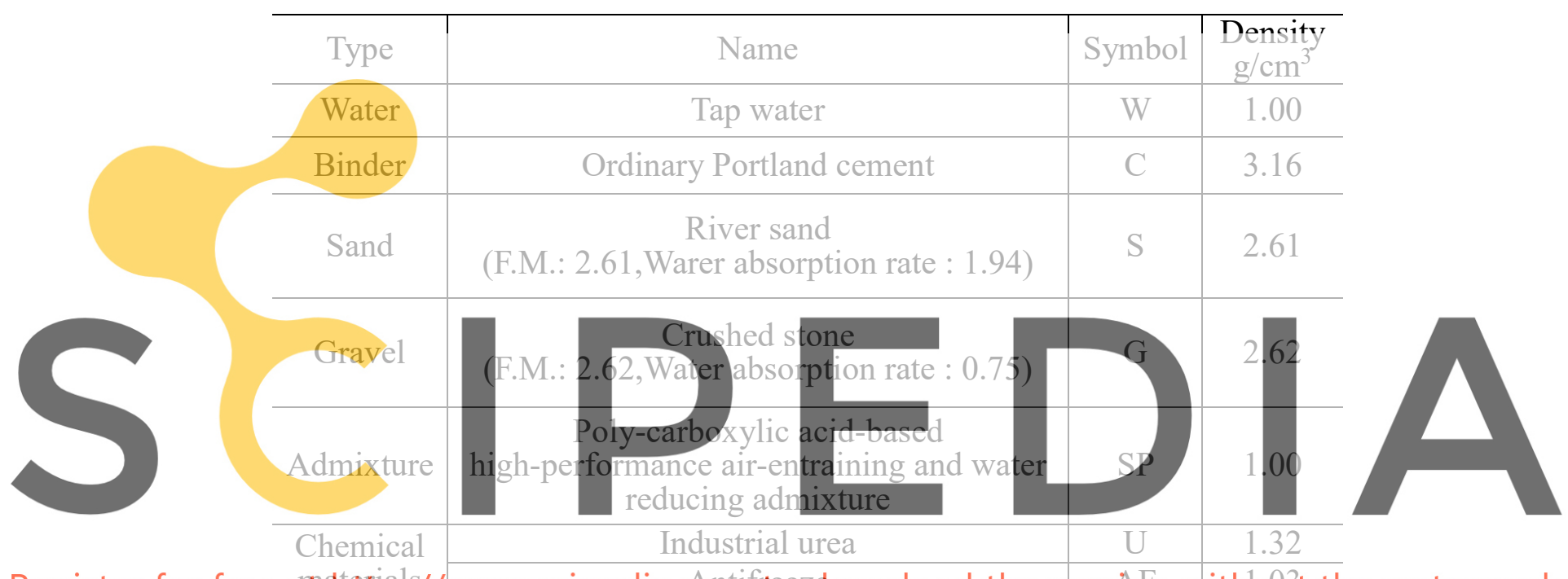

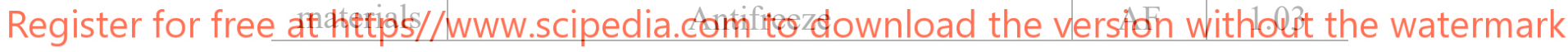

Table 3. Mixing condition and properties of fresh mortar.

\begin{tabular}{|c|c|c|c|c|c|c|}
\hline \multirow{2}{*}{$\mathrm{W} / \mathrm{C}(\%)$} & \multirow{2}{*}{$\mathrm{S} / \mathrm{C}$} & \multicolumn{3}{|c|}{ Unit quantity $\left(\mathrm{kg} / \mathrm{m}^{3}\right)$} & \multirow{2}{*}{ Air volume $(\%)$} & \multirow{2}{*}{$\begin{array}{l}\text { Flow } \\
(\mathrm{mm})\end{array}$} \\
\hline & & $\mathrm{W}$ & $\mathrm{C}$ & $\mathrm{S}$ & & \\
\hline 50 & 2.3 & 293 & 550 & 1247 & 2.4 & 220 \\
\hline
\end{tabular}

\subsubsection{Test items}

(1) 15 strokes flow test

The 15 stroke flow test was carried out in accordance with ISO 6792009.

(2) Air volume test

The air volume test was carried out in accordance with ISO 1920-2 2016.

(3) Drying shrinkage test

The drying shrinkage test was carried out in accordance with ISO 1920-8. Figure 4 shows the method used for this test. Prismatic specimens $(40 \times 40 \times 160 \mathrm{~mm})$ were made for this test. The specimens were demolded one day after mixing, and this day was taken as day 0 for the start of air curing. The specimens were cured in a room at a constant temperature of $20 \pm 3\left({ }^{\circ} \mathrm{C}\right)$ and 60 
$\pm 5 \%$ relative humidity and changes in length and mass were measured. Next, some specimens were soaked in a 30\% antifreeze solution for 1 minute, 10 minutes, and 30 minutes (Table 1). Other specimens were not soaked. Changes in the length and mass of all of the specimens were measured for 91 days.

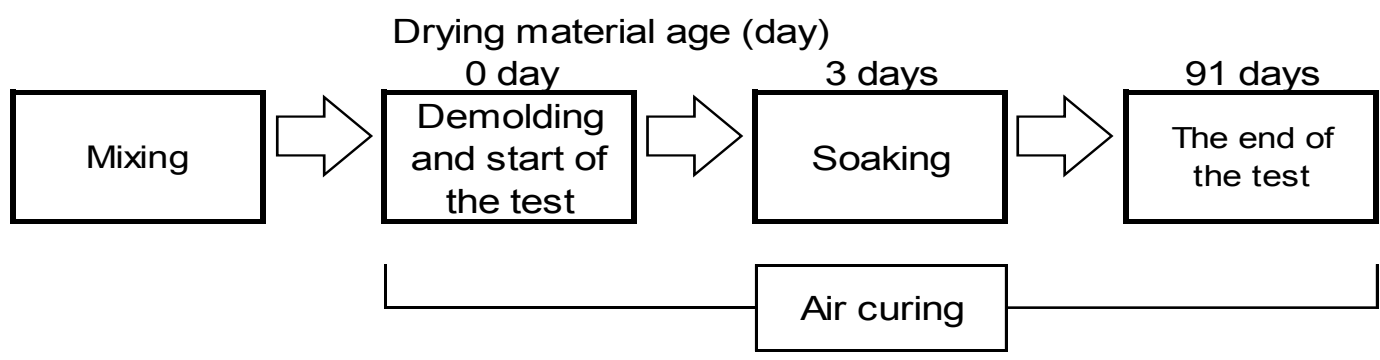

Figure 4. Method used for drying shrinkage test.

\subsubsection{Test results}

The results of the drying shrinkage test of mortar show that the specimens soaked in a $30 \%$ antifreeze solution exhibited a greater drying shrinkage effect than the specimens that were not soaked (Fig. 5). Moreover, the effect became larger as the soaking time increased.
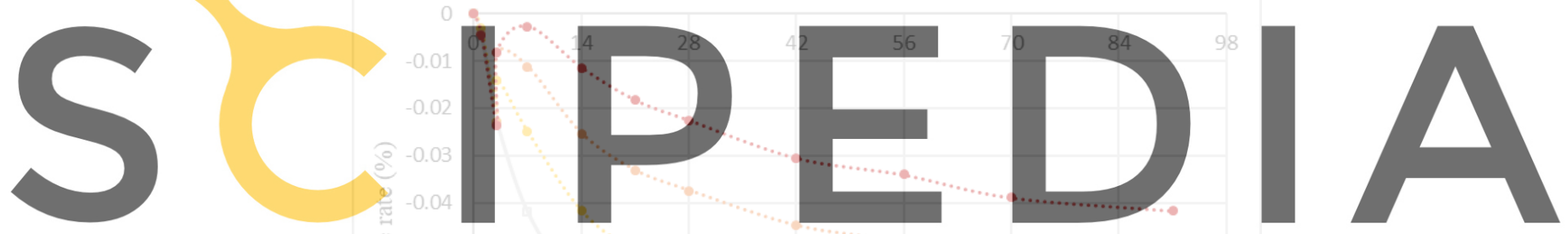

Register for free at http๊ps//www.scipedia.com to download the version without the watermark

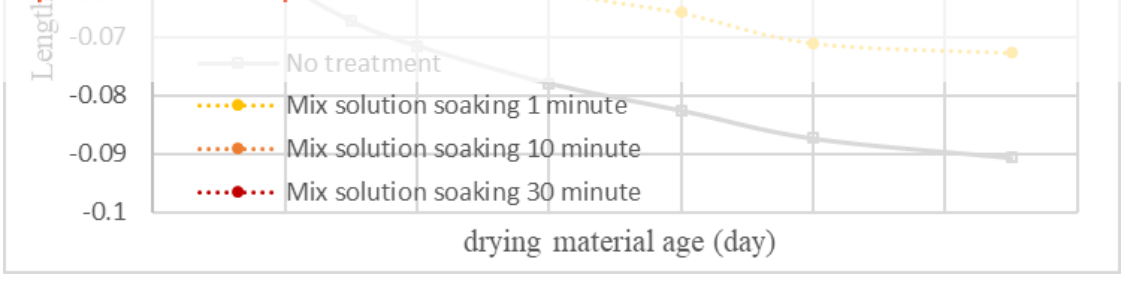

Figure 5. Drying shrinkage test of mortar.

\subsection{Concrete Soaked in 30 \% Antifreeze Solution}

Since the $30 \%$ antifreeze solution clearly reduced drying shrinkage in mortar, the same experiment was conducted using concrete.

\subsubsection{Materials}

The materials used were the same as those described in section 3.3.1 above.

\subsubsection{Mixing conditions}

Table 4 shows the mixing conditions and properties of fresh concrete. The target values of the 
freshness properties were $8.0 \pm 1.5 \mathrm{~cm}$ for slump, $4.5 \pm 1.5 \%$ for air volume.

Table 4. Mixing conditions and properties of fresh concrete.

\begin{tabular}{c|c|c|c|c|c||c|c}
\hline \multirow{2}{*}{$\begin{array}{c}\text { W/C } \\
(\%)\end{array}$} & \multicolumn{4}{|c|}{$\begin{array}{c}\text { Unit quantity } \\
\left(\mathrm{kg} / \mathrm{m}^{3}\right)\end{array}$} & $\begin{array}{c}\text { Addition rate } \\
(\mathrm{C} \times \%)\end{array}$ & $\begin{array}{c}\text { Air volume } \\
(\%)\end{array}$ & $\begin{array}{c}\text { Slump } \\
(\mathrm{cm})\end{array}$ \\
\cline { 2 - 7 } & $\mathrm{W}$ & $\mathrm{C}$ & $\mathrm{S}$ & $\mathrm{G}$ & $\mathrm{SP}$ & 4.0 & 8.5 \\
\hline 50 & 170 & 340 & 798 & 969 & 0.10 & 4 \\
\hline
\end{tabular}

\subsubsection{Mixing method}

A pan type mixer with a nominal capacity of 55 (L) was used for mixing. First, cement, sand, and gravel were mixed for 15 seconds. Next, water mixed with SP was added and mixed for 60 seconds. Finally, the concrete was discharged.

\subsubsection{Test items}

\section{(1) Concrete slump test}

The concrete slump test was carried out in accordance with ISO 1920-2 2005.

\section{(2) Air volume test}

The air volume test was carried out in accordance with ISO 1920-2 2016.

\section{(3) Drying shrinkage test}

The drying shrinkage test was carried out using the same method and room conditions used for

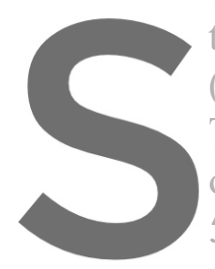

the mortar experiment,

(4) Compressive strength test

The compressive strength test

on day 1 , the specimens were

$5 \%$ relative humidity.

strength tests were conducted at age of 7 and 28 days.

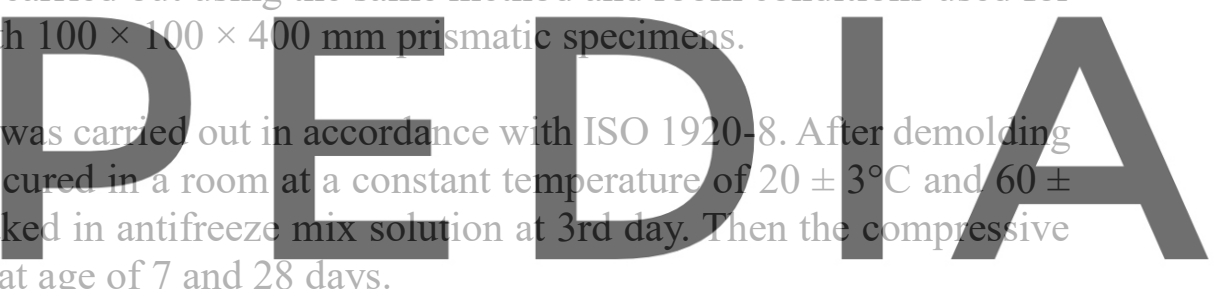

\section{Register f९.4.}

The test results confirmed that soaking concrete in a 30\% antifreeze solution reduces drying

shrinkage (Fig. 6). Previous studies have shown a drying shrinkage reduction effect when specimens are soaked in a urea solution. This study showed that antifreeze solutions also reduce drying shrinkage. Urea recrystallizes in the voids of concrete after soaking in an antifreeze solution also reduce drying shrinkage due to the recrystallization of urea in the voids of the concrete.

Figure 7 shows the results of the compressive strength test. As shown in previous studies, this study confirmed that soaking concrete in an antifreeze solution increased the compressive strength. Moreover, the strength increased as the soaking time increased. The urea crystals help improve compressive strength. 

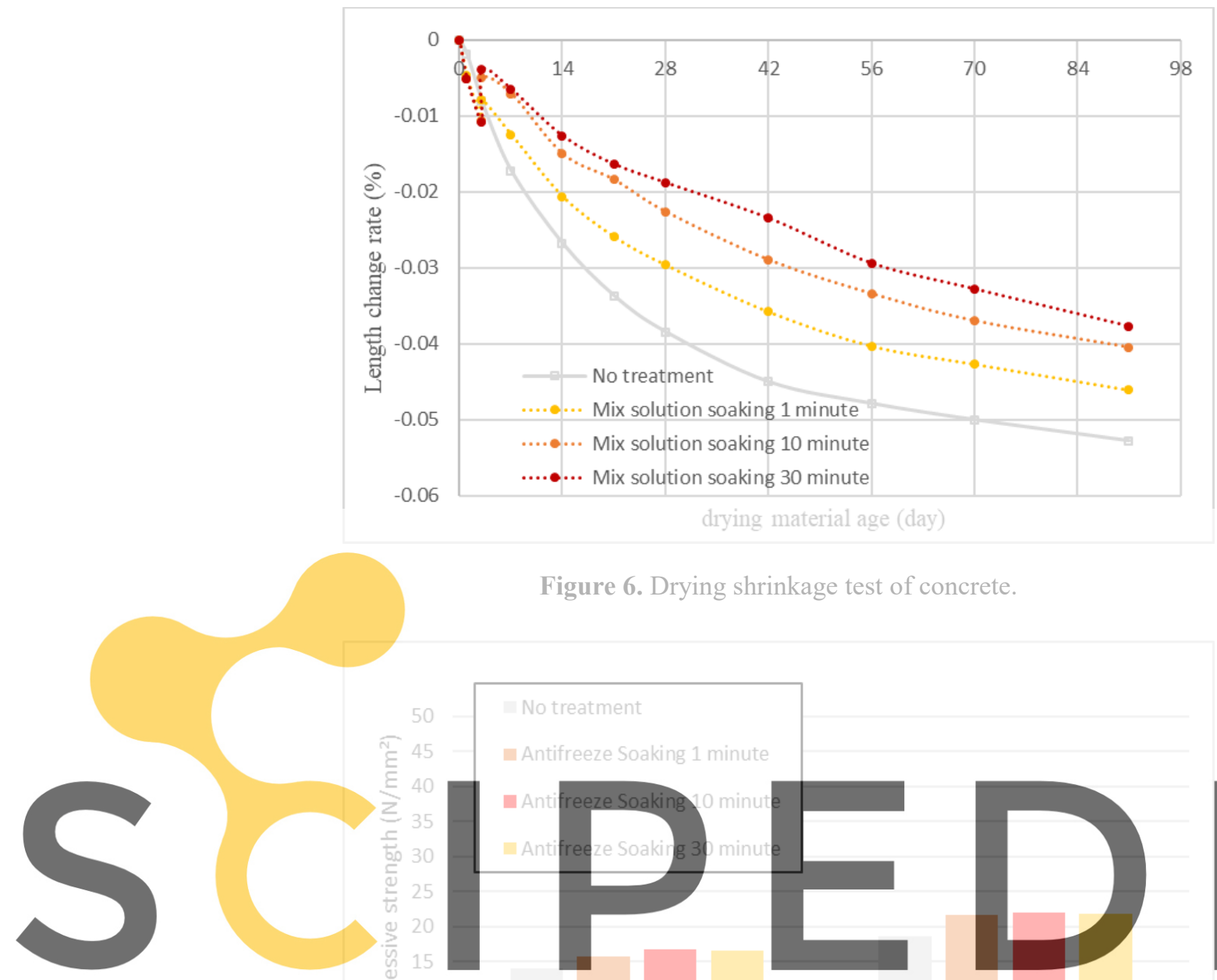

Figure 6. Drying shrinkage test of concrete.

Register for free at https //www.scipedia.com to download the version without the watermark

Age (day)

Figure 7. Compressive strength.

\subsection{Conclusion}

This study showed that the crystallization temperature of urea can be lowered by mixing it with antifreeze. Furthermore, soaking the concrete in an antifreeze solution reduces drying shrinkage, as indicated by the lower length change rate in the drying shrinkage test. These results confirm that an antifreeze solution can be used as a drying shrinkage reduction agent in cold weather. The practical application of this method in the field, however, requires further study.

\section{ORCID}

Takumi Sato: https://orcid.org/0000-0002-8181-3489

Hiromi Fujiwara: https://orcid.org/0000-0003-3032-480X

Masanori Maruoka: https://orcid.org/0000-0002-3041-0700

Liu Lingling: https://orcid.org/0000-0001-9450-7598 


\section{References}

Kawai T and Sakata K. (2007). Properties of concrete incorporating urea. Proceeding of the Japan Concrete Institute, Volume 29, 639-644.

Liu L, Fujiwara H, and Maruoka M. (2017). Development of a new drying shrinkage reducing agent of concrete by spraying on surface of concrete. Proceeding of the Japan Concrete Institute, Volume 39, 415-420.

Liu L, Fujiwara H, Maruoka M, and Shirayama K. (2018). Development of a drying shrinkage reducing agent of concrete by spraying and brushing urea solution. Proceeding of the Japan Concrete Institute, Volume 41, 407412.
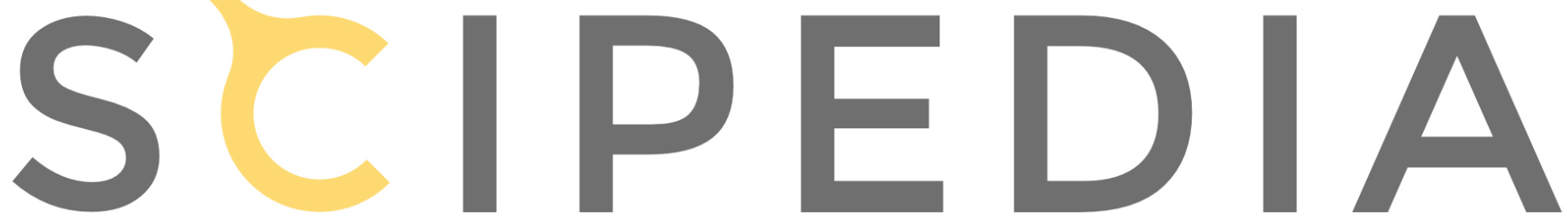

Register for free at https//www.scipedia.com to download the version without the watermark 